\title{
The relationship between the degree of malnutrition and changes in selected parameters of the immune response in critically ill patients
}

\author{
MARTA STELMASIAK ${ }^{1,2}$, BARBARA JOANNA BAEAN ${ }^{3}$, MAEGORZATA MIKASZEWSKA-SOKOLEWICZ4, \\ GRZEGORZ NIEWIŃSKI ${ }^{5}$, KATARZYNA KOSAEKA ${ }^{2}$, EWELINA SZCZEPANOWSKA2, \\ ROBERT SEOTWINSSKR
}

${ }^{1}$ Faculty of Medical and Health Sciences, Kazimierz Pulaski University of Technology and Humanities in Radom, Poland ${ }^{2}$ Department of Immunology, Biochemistry and Nutrition, Medical University of Warsaw, Warsaw, Poland

${ }^{3}$ Department of Prevention of Environmental Hazards, Allergology and Immunology, Medical University of Warsaw, Warsaw, Poland ${ }^{4}$ I Department of Anesthesiology and Intensive Care, Medical University of Warsaw, Warsaw, Poland ${ }^{5}$ II Department of Anesthesiology and Intensive Care, Medical University of Warsaw, Warsaw, Poland

\begin{abstract}
Patients treated in intensive care units (ICUs) are at high risk of malnutrition and the resulting homeostasis, metabolic, histological and immunological disorders, especially leading to organ failure and increased susceptibility to infection. In 163 patients with malnutrition [mild in 33 (19.6\%), moderate in $69(42.9 \%)$, severe in $61(37.4 \%)]$ treated in the ICU, changes in the concentration of selected proteins [interleukin (IL)-1Ra, tumor necrosis factor $\alpha(T N F-\alpha)$, soluble tumour necrosis factor receptor-1 (sTNFR1), IL-6, IL-10, sTLR4, MyD88, A20, HSP70, HMGB1] were examined. In the whole group of malnourished patients, median values of STNFR1, TNF- $\alpha, I L-6, T L R 4, I L-1 R a$ were significantly increased, while the levels of MyD88 and A20 proteins were significantly reduced (in comparison to the well-nourished healthy group). Only the STNFR1 protein showed a significant difference between mild, moderate and severe malnutrition, and increased concentrations as the severity of malnutrition increased (the correlation study found that as the degree of malnutrition increased, the sTNFRI concentrations increased; $p=0.0000, R=0.5442$ ). It was observed that death was significantly more frequent in the group of patients who on the first day of hospitalization in the ICU scored 5 or more points on the NRS 2002 scale $(p=0.0004)$. In the patients who died significantly higher concentrations of STNFR1, IL-6, IL-10, HSP70 were observed in comparison to the patients who survived. The present results are encouraging and indicate the desirability of undertaking multicentre clinical trials including monitoring of STNFR1 in assessing the severity of malnutrition and immune disorders in the first hours after admission to the ICU, because it can be assumed that without early diagnosis of innate immunity disorders any attempts at their modulation may be ineffective.
\end{abstract}

Key words: malnutrition, innate immune response, ICU, critically ill, sTNFRI.

(Cent Eur J Immunol 2021; 46 (1): 82-91)

\section{Introduction}

Despite the progress in intensive care, mortality among patients treated in the intensive care unit (ICU) is still very high and in severe infections with multiorgan failure may reach even from $17 \%$ [1] to $40 \%$ [2]. The main factors adversely affecting the prognosis include malnutrition and stress starvation for seriously ill patients. Nutritional disorders in septic patients treated in ICUs may be due to starvation, malabsorption and digestion, impaired metabolism, associated infections and multi-organ failure. Intensive care malnutrition is a global problem and the frequency is $78.1 \%$ in developing countries, and $50.8 \%$ in developed countries [3]. Another study found chronic malnutrition in $56 \%$ of patients, protein-energy malnutrition (PEM) in $12 \%$, while only $32 \%$ were well nourished [4]. The risk of malnutrition is even burdened with up to $100 \%$ of patients treated in the ICU [5]. It has been reported that malnutrition can increase hospital mortality by up to five times [6]. A 28-day survival study found a $33 \%$ increase in death risk in malnourished patients treated in ICUs [3].

Correspondence: Marta Stelmasiak, Department of Immunology, Biochemistry and Nutrition, Medical University of Warsaw, Warsaw,

Poland, e-mail: mjstelmasiak@gmail.com

Submitted: 28.08.2019; Accepted: 7.12.2019 
Research to date indicates a lack of effective nutrition assessment tools in the ICU, which hinders early implementation and monitoring of nutritional treatment, and could reduce mortality [7]. Patients treated in ICUs, primarily septic patients or patients after major trauma or extensive surgery, are at high risk of malnutrition and the resulting homeostasis, metabolic, histological and immunological disorders leading to organ failure and increased susceptibility to infection [8-15]. Especially in this group of patients, careful and frequent monitoring of the nutritional status is advisable, because with the length of hospitalization the risk of deterioration of malnutrition, and thus also the general condition, increases [5]. In the light of these studies, it may be helpful to supplement the routine assessment of nutritional status with selected immunological tests, the results of which would correlate with the degree of malnutrition. Extending the diagnosis of malnutrition by assessing immune disorders would allow selection of appropriate immunomodulatory nutrition.

Malnutrition intensifies both quantitative and qualitative disorders of cellular immunity. However, the mechanisms of the effect of malnutrition on the functioning of a non-specific immune response with significant prognostic significance in sepsis are not fully understood due to the small number of studies. The effect of inflammation on malnutrition is also unknown. In the research of Sauerwein et al. [16], it has been found that inflammation may play a key role in the pathogenesis of kwashiorkor malnutrition. The main trigger may be invasion by microorganisms, translocation of bacterial products or other previously unidentified stimuli interacting with the environment in nutritional stress, which results in the inability to control the initiated inflammatory response [16]. In the past, it has been shown that malnutrition leads to impairment of: phagocytosis [17], the chemotactic capacity of neutrophils and monocytes, the complement system, especially the $\mathrm{C} 3$ protein responsible for opsonization [18], and the weakening of the function of antigen presenting cells [19]. On the other hand, sepsis may increase the apoptosis of immune cells (to a lesser extent neutrophils), which is another reason for increasing immunity disorders [20]. Unfortunately, the authors of this work did not pay attention to the accompanying severe infection and worsening malnutrition, and did not attempt to correlate the degree of malnutrition with impaired innate immune response. It is known that malnutrition increases the susceptibility to infections, extends the hospitalization time and increases the risk of complications associated with metabolic and immunological disorders as well as the costs of treatment in the ICU [21, 22]. However, despite the fact that for many years $[23,24]$ attention has been paid to the influence of malnutrition on the immune system, sepsis and prognosis, there are still no precise recommendations regarding the monitoring of immune disorders resulting from malnutrition, especially in critically ill patients treated in ICUs.

In the present understanding of sepsis, as a disease resulting from a dysregulated immune response of a patient to infection [25], malnutrition is considered an aggravating factor hindering recovery, but no attempt has been made to assess the relationship between the degree of malnutrition and changes in immunity in patients with severe infections. This applies especially to the large group of patients hospitalized in the ICU and who have developed a chronic critical illness (CCI). The criteria for diagnosing CCI include: hospitalization for more than 8 days, recurrent infections, organ failure, malnutrition, weakness, cognitive decline, and often no recovery or long-term survival [26, 27]. It is known that in this group of patients, malnutrition should be treated as a disease and an independent risk factor for complications and mortality, which requires appropriate diagnostics and appropriate nutritional treatment [28]. An important factor aggravating malnutrition and immune disorders is primarily the growing deficiency of immunologically active substances (mainly amino acids, fatty acids, antioxidants) often leading to the development of persistent inflammation and immunosuppression and catabolism syndrome (PICS). The PICS is a frequent consequence of the systemic inflammatory response syndrome (SIRS) and the compensatory anti-inflammatory response syndrome (CARS) [29]. PICS has been defined as chronic inflammation with manageable organ failure, ongoing protein catabolism and poor nutritional status leading to cachexia, poorer wound healing and immunosuppression of both innate and acquired immunity and with increased susceptibility to secondary infections. It usually occurs after a long stay in the ICU (> 14 days). Indirect markers of the PICS are increased concentration of CRP protein (above $150 \mu \mathrm{g} / \mathrm{dl}$ ), decrease in concentration of retinol binding protein (below $10 \mu \mathrm{g} / \mathrm{dl}$ ) - indicative of chronic inflammation, decrease in lymphocyte count (below $800 / \mu \mathrm{l}$ ) - which is a symptom of immunosuppression, and catabolism and severe malnutrition greater than $10 \%$ weight loss during hospitalization or body mass index (BMI) below $18 \mathrm{~kg} / \mathrm{m}^{2}$, reduction of albumin concentration below $3 \mathrm{mg} / \mathrm{dl}$, and decrease of prealbumin concentration below $20 \mu \mathrm{g} / \mathrm{dl}$. It is believed that PICS underlies CCI, and its understanding is necessary to clarify the overarching mechanism of immune discretion in severe infections. In the PICS, immature cells with suppressor activity are derived from myeloid lineage (myeloid-derived suppressor cells - MDSC). They appear as a result of so-called emergency myelopoiesis, which is an attempt to meet the increased demand for immunocompetent cells. However, MDSC cells have a negative effect on T lymphocyte function by depleting arginine and producing nitric oxide. MDSC may also contribute to persistent inflammation and increased immunosuppression through the production of inflammatory mediators such as cytokines [e.g. tumor necrosis factor $\alpha$ (TNF- $\alpha$ ), interleukin (IL)-10], nitric oxide (NO) and reactive oxygen species. It has been shown that the MDSC population increases rapidly in patients with sepsis and remains elevated for several weeks, which translates into a critical condition of patients $[26,30]$. Important- 
ly, patients who had the largest increase in MDSC had an early death, or hospitalization was prolonged due to lack of improvement. The rapid decline in MDSC was associated with early discharge from the ICU [26]. One of the hypotheses of PICS treatment assumes that properly formulated nutritional therapy, enabling anabolic processes, assuming an adequate supply of arginine and other immunomodulatory compounds, may contribute to allowing immune cells to mature and take on function [31]. It is known, however, that the supply of arginine, especially in septic conditions with severe SIRS reaction, is still not recommended in severely treated patients in the ICU (source of NO, relaxation of small vessels, possibility of worsening symptoms of septic shock), as it may increase mortality [7, 32].

The currently contradictory results of nutritional treatment leading to the reduction of immunomodulatory nutrition in the group of seriously ill patients treated in ICU are primarily associated with the "lack of matching" this type of nutrition to the metabolic possibilities of a given patient, the degree of malnutrition and nutrient demand as well as the current state of the immune response to malnutrition, injury, infection or treatment (usually no monitoring). Also differences in the supply of nitrogen, calories, time, route of administration and doses of immunomodulators make the results of large meta-analyses difficult to compare. The lack of precise methods/markers enabling monitoring of nutritional status and immunological activity is another factor hindering the "adjustment of nutrition" to the condition of patients and means that nutritional treatment may be ineffective and burdened with complications increasing mortality in the ICU. Currently, according to ESPEN recommendations, it is assumed that within 48 hours after the diagnosis of sepsis, in hemodynamically stable patients, enteral feeding should be started, caloric intake should be reduced, e.g. to $500 \mathrm{kcal} / \mathrm{day}$, and increased as nutrition is tolerated; it is suggested to avoid mixtures enriched with immunomodulating components [33]. In the randomized TICACOS study, it was found that providing patients with the right number of calories in relation to their energy expenditure significantly reduced their mortality [34].

Based on the assumption that significant causes of high mortality in critically ill patients are not only immune disorders, but above all deepening malnutrition, the present study attempts to establish the relationship between the degree of malnutrition and changes in selected parameters of the innate immune response. An attempt was also made to establish immunological indicators differentiating the degree of malnutrition with a parallel assessment of the effect of nutritional status on prognosis (mortality) in critically ill patients.

\section{Material and methods}

\section{Patients and healthy donors}

A total of 163 patients admitted to the ICUs I and II of the Department of Anaesthesiology and Intensive Therapy,
Medical University of Warsaw (average age $57 \pm 18$ years; $116 \mathrm{M} / 47 \mathrm{~F}$ ) in the years 2014-2018 were qualified for the study.

The study included a group of critically ill patients, in which $37(23 \%)$ patients had multiorgan failure, and $86(53 \%)$ patients required mechanical ventilation. In this group, $75(46 \%)$ had severe infections, including $51(31 \%)$ with sepsis and $24(15 \%)$ with septic shock. The remaining 88 (54\%) patients were people without concomitant severe infections. There were 50 (30.7\%) deaths, including $42(84 \%)$ in patients with moderate or severe malnutrition. In 22 cases death in the course of severe infection was observed, and in 28 cases death was observed in the group of patients who were not diagnosed with severe infection. The most common cause of death in this group was sudden cardiac arrest or trauma after traffic accidents. Severity and risk of death were assessed on the APACHE II scale (median for the whole group was 26 points, range 5-51 points). The severity of infection was diagnosed according to the ACCP/SCCM criteria (American College of Chest Physicians/Society of Critical Care Medicine) and European Intensive Care Society $[25,33,35,36]$. The diagnosis of severe infections was based on clinical criteria with an additional of suspected or confirmed infection in the case of sepsis, and the addition of organ disfunction in the case of septic shock [25]. The nutrition status and nutritional requirements were assessed using the NRS 2002 scale (Nutrition Risk Screening 2002) [37]. This scale has a maximum of 3 points (range: 0-3 points) in the screening of impaired nutritional status; there are also 3 points for increase in requirements caused by severe disease (range 0-3 points), and there is an extra point for age $\geq 70$ years. According to the NRS 2002 scale the malnourished patients were divided into 3 groups (1-2 points on the NRS 2002 scale - mild malnutrition, 3-4 points - moderate malnutrition, 5-7 points - severe malnutrition). During the ICU stay, routine laboratory and bacteriological tests were performed and the whole group was monitored for the course of the disease and mortality over 28 days.

Patients older than 80 years of age, after chemo- and radiation therapy, with diabetes, chronic liver and kidney diseases, after transplantation, immunosuppressive treatment and those receiving chronic steroids or non-steroidal anti-inflammatory drugs were not eligible for the study.

The control group consisted of 48 healthy volunteers of similar age and sex, from whom peripheral blood (plasma) was collected for immunological tests. According to the NRS 2002 scale, the nutritional status of the control group did not deviate from the norm.

The research was approved by the Bioethics Committee of the Medical University of Warsaw (KB/149/2008). All patients gave permission to perform tests and describe their medical history. All procedures were in line with the Helsinki Declaration. 


\section{Determination of protein concentrations}

Peripheral blood for immunological testing was collected on the first day after admission to the ICU. For testing the concentration of selected proteins [TNF- $\alpha$, soluble tumour necrosis factor receptor-1 (sTNFR1), IL-1Ra, IL-6, IL-10, sTLR4, MyD88, A20, HSP70, HMGB1] commercial sets for their quantitative enzyme-linked immunosorbent assay (ELISA) method were used in peripheral blood plasma (R\&D Systems: TNF- $\alpha$, sTNFR1, IL-1Ra, IL-6, IL-10, HSP70, HMGB1; EIAab: sTLR4, Myd88, A20) following the manufacturer's instructions. Plasma was obtained from venous blood collected on heparin. The blood sample was centrifuged (2000 rpm for $30 \mathrm{~min}$ ), plasma was isolated, which was then frozen/stored at $-80^{\circ} \mathrm{C}$ for later use. The lower limit of test sensitivity was $0.5 \mathrm{pg} / \mathrm{ml}$ for TNF- $\alpha, 0.70 \mathrm{pg} / \mathrm{ml}$ for IL-6, $3.9 \mathrm{pg} / \mathrm{ml}$ for IL-10, and $2.2 \mathrm{pg} / \mathrm{ml}$ for IL-1Ra; sTNFR1 $0.43 \mathrm{pg} / \mathrm{ml}$, for sTLR4 $0.625 \mathrm{pg} / \mathrm{ml}$, for MyD88 $0.156 \mathrm{pg} / \mathrm{ml}$, for A20 $0.312 \mathrm{pg} / \mathrm{ml}$, for HSP70 $6.79 \mathrm{ng} / \mathrm{ml}$, for HMGB1 $18.75 \mathrm{pg} / \mathrm{ml}$. The ELISA reading was made using a DIALAB ELX 808 spectrophotometer and Gen51.10 software at a wavelength of $\lambda=450 \mathrm{~nm}$. The concentration of the tested proteins was evaluated by comparing the obtained absorbance values with a standard curve prepared by determining the absorbance of samples of known concentration. The results are presented as median concentrations in $\mathrm{pg} / \mathrm{ml}$.

\section{Statistical analysis}

Statistica 13.1 was used for statistical study. MannWhitney $U$ test was used to compare the immunological parameters determined in the study group (with malnutrition) and control (with normal nutritional status), compare individual subgroups (with varying degrees of malnutrition), and compare the group in which death or survival occurred. The Kruskal-Wallis ANOVA test was used to compare the differences in protein concentrations between individual subgroups with different levels of malnutrition and the control group. A median test was used to compare differences in the level of malnutrition between the groups of patients who died or survived. The correlation between the concentration of determined proteins and the APACHE II scale and the NRS 2002 scale was tested by the Spearman rho test. $P$ values of $<0.05$ were considered to be statistically significant.

\section{Results}

Malnutrition of varying severity was found in the whole group of patients studied, including mild in 33 cases $(19.6 \%)$, moderate in 69 cases $(42.9 \%)$ and severe in 61 cases $(37.4 \%)$. In the whole group of malnourished patients, median values of sTNFR1, TNF- $\alpha$, IL-6, TLR4, IL-1Ra were significantly increased, while the levels of MyD88 and A20 proteins were significantly decreased (in the comparison to the healthy donor group, with normal nutritional status). There were no significant differences in the median levels of IL-10, HSP70 and HMGB1 proteins $(p>0.05)$ between those groups. The values of median concentrations for the whole group of malnourished patients and people with normal nutritional status (control group) are presented in Table 1.

Depending on the degree of malnutrition in the subgroups of patients with mild, moderate and severe malnutrition, significant differences were found in the concentrations of selected proteins compared to normal nutritional status. In the study of the significance of differences between sTNFR1 protein values in the next 3 subgroups with malnutrition (mild, moderate, severe) and the group with normal nutritional status, significant differences were found in each of the subgroups; also a significant increase in medians was found in the patient subgroup concentrations, which achieved the highest values in patients with severe malnutrition. Median concentrations of tested pro-

Table 1. Median values $(\mathrm{pg} / \mathrm{ml})$ of immunological parameters in the studied group of malnourished patients and in the control group with normal nutritional status

\begin{tabular}{|c|c|c|c|c|c|c|c|c|c|c|}
\hline \multirow{2}{*}{$\begin{array}{l}\text { Nutritional } \\
\text { status }\end{array}$} & \multicolumn{10}{|c|}{ Immunological parameters (pg/ml) } \\
\hline & sTNFR1 & IL-6 & sTLR4 & TNF- $\alpha$ & MyD88 & A20 & IL-1Ra & IL-10 & HSP70 & HMGB1 \\
\hline $\begin{array}{l}\text { Malnourished } \\
\text { group } \\
\text { (researched } \\
\text { group) } \\
n=163\end{array}$ & $\begin{array}{l}8992.60 \\
\text { range: } \\
21.31- \\
47921.30\end{array}$ & $\begin{array}{c}47.91 \\
\text { range: } \\
0.04- \\
960.49\end{array}$ & $\begin{array}{c}0.47 \\
\text { range: } \\
0.45- \\
1.10\end{array}$ & $\begin{array}{c}25.41 \\
\text { range: } \\
1.99- \\
491.85\end{array}$ & $\begin{array}{c}0.00 \\
\text { range: } \\
0.00- \\
14712.00\end{array}$ & $\begin{array}{c}1.35 \\
\text { range: } \\
0.14- \\
20.98\end{array}$ & $\begin{array}{c}616.57 \\
\text { range: } \\
104.48- \\
4200.00\end{array}$ & $\begin{array}{c}0 \\
\text { range: } \\
0.00- \\
918.69\end{array}$ & $\begin{array}{c}0.10 \\
\text { range: } \\
0.00- \\
11.81\end{array}$ & $\begin{array}{c}0.00 \\
\text { range: } \\
0.00- \\
3.65\end{array}$ \\
\hline $\begin{array}{l}\text { Correct nutrition } \\
\text { (control group) } \\
n=48\end{array}$ & $\begin{array}{c}200.32 \\
\text { range: } \\
27.11- \\
4864.50\end{array}$ & $\begin{array}{c}1.50 \\
\text { range: } \\
0.00- \\
613.05\end{array}$ & $\begin{array}{c}0.46 \\
\text { range: } \\
0.45- \\
0.55\end{array}$ & $\begin{array}{c}13.29 \\
\text { range: } \\
0.36- \\
321.96\end{array}$ & $\begin{array}{c}476.00 \\
\text { range: } \\
0.00- \\
19168.00\end{array}$ & $\begin{array}{c}5.20 \\
\text { range: } \\
0.06- \\
20.50\end{array}$ & $\begin{array}{c}387.42 \\
\text { range: } \\
9.74- \\
2665.70\end{array}$ & $\begin{array}{c}0 \\
\text { range: } \\
0.00- \\
21.77\end{array}$ & $\begin{array}{c}0.22 \\
\text { range: } \\
0.00- \\
2.68\end{array}$ & $\begin{array}{c}0.00 \\
\text { range: } \\
0.00- \\
3.88\end{array}$ \\
\hline $\begin{array}{l}U \text { Mann-Whitney } \\
\text { test }\end{array}$ & $p=0.0000$ & $p=0.0000$ & $p=0.0000$ & $p=0.0000$ & $p=0.0000$ & $p=0.0007$ & $p=0.0117$ & $p>0.05$ & $p>0.05$ & $p>0.05$ \\
\hline
\end{tabular}


Table 2. Median concentrations of tested proteins for individual subgroups of patients differing in the degree of malnutrition and comparison with the control group

\begin{tabular}{|c|c|c|c|c|c|c|c|c|c|c|}
\hline \multirow{2}{*}{$\begin{array}{l}\text { Nutritional } \\
\text { status }\end{array}$} & \multicolumn{10}{|c|}{ Immunological parameters (pg/ml) } \\
\hline & sTNFR1 & IL-6 & sTLR4 & TNF- $\alpha$ & MyD88 & A20 & IL-1Ra & IL-10 & HSP70 & HMGB1 \\
\hline $\begin{array}{l}\text { Mild } \\
\text { malnutrition }\end{array}$ & $\begin{array}{c}705.46 \\
\text { range: } \\
21.31- \\
23278.90\end{array}$ & $\begin{array}{c}39.28 \\
\text { range: } \\
1.42- \\
647.03\end{array}$ & $\begin{array}{c}0.46 \\
\text { range: } \\
0.46- \\
0.53\end{array}$ & $\begin{array}{c}25.50 \\
\text { range: } \\
8.33- \\
194.98\end{array}$ & $\begin{array}{c}0.00 \\
\text { range: } \\
0.00- \\
14712.00\end{array}$ & $\begin{array}{c}1.85 \\
\text { range: } \\
0.23- \\
15.72\end{array}$ & $\begin{array}{c}708.82 \\
\text { range: } \\
399.07- \\
3074.65\end{array}$ & $\begin{array}{c}0.00 \\
\text { range: } \\
0.00- \\
27.888\end{array}$ & $\begin{array}{c}0.03 \\
\text { range: } \\
0.00- \\
1.34\end{array}$ & $\begin{array}{c}0.00 \\
\text { range: } \\
0.00- \\
3.65\end{array}$ \\
\hline $\begin{array}{l}\text { Mild } \\
\text { malnutrition } \\
\text { vs. control } \\
\text { group }\end{array}$ & $p=0.0238$ & $p=0.0001$ & $p=0.0305$ & $p=0.0009$ & $p=0.0080$ & $p>0.05$ & $p>0.05$ & $p>0.05$ & $p>0.05$ & $p>0.05$ \\
\hline $\begin{array}{l}\text { Moderate } \\
\text { malnutrition }\end{array}$ & $\begin{array}{c}1430.20 \\
\text { range: } \\
161.91- \\
45572.80\end{array}$ & $\begin{array}{c}48.95 \\
\text { range: } \\
0.03- \\
851.93\end{array}$ & $\begin{array}{c}0.47 \\
\text { range: } \\
0.45- \\
0.55\end{array}$ & $\begin{array}{c}21.84 \\
\text { range: } \\
2.00- \\
491.85\end{array}$ & $\begin{array}{c}0.00 \\
\text { range: } \\
0.00- \\
7520.00\end{array}$ & $\begin{array}{c}2.49 \\
\text { range: } \\
0.14- \\
20.98\end{array}$ & $\begin{array}{c}575.80 \\
\text { range: } \\
146.69- \\
4145.01\end{array}$ & $\begin{array}{c}0.00 \\
\text { range: } \\
0.00- \\
918.69\end{array}$ & $\begin{array}{c}0.11 \\
\text { range: } \\
0.00- \\
11.81\end{array}$ & $\begin{array}{c}0.00 \\
\text { range: } \\
0.00- \\
0.97\end{array}$ \\
\hline $\begin{array}{l}\text { Moderate } \\
\text { malnutrition } \\
\text { vs. control } \\
\text { group }\end{array}$ & $p=0.0000$ & $p=0.000$ & $p=0.0001$ & $p=0.0000$ & $p=0.0009$ & $p=0.0401$ & $p>0.05$ & $p>0.05$ & $p>0.05$ & $p>0.05$ \\
\hline $\begin{array}{l}\text { Severe } \\
\text { malnutrition }\end{array}$ & $\begin{array}{l}18999.70 \\
\text { range: } \\
283.67- \\
47921.30\end{array}$ & $\begin{array}{c}48.03 \\
\text { range: } \\
2.38- \\
960.49\end{array}$ & $\begin{array}{c}0.46 \\
\text { range: } \\
0.45- \\
1.10\end{array}$ & $\begin{array}{c}27.18 \\
\text { range: } \\
2.62- \\
252.08\end{array}$ & $\begin{array}{c}0.00 \\
\text { range: } \\
0.00- \\
13536.00\end{array}$ & $\begin{array}{c}0.63 \\
\text { range: } \\
0.06- \\
20.50\end{array}$ & $\begin{array}{c}925.00 \\
\text { range: } \\
9.74- \\
3074.65\end{array}$ & $\begin{array}{c}0.00 \\
\text { range: } \\
0.00- \\
27.88\end{array}$ & $\begin{array}{c}0.08 \\
\text { range: } \\
0.00- \\
2.84\end{array}$ & $\begin{array}{c}0.00 \\
\text { range: } \\
0.00- \\
0.00\end{array}$ \\
\hline $\begin{array}{l}\text { Severe } \\
\text { malnutrition } \\
\text { vs. control } \\
\text { group }\end{array}$ & $p=0.0000$ & $p=0.000$ & $p=0.0073$ & $p=0.0000$ & $p=0.0000$ & $p=0.0001$ & $p=0.0205$ & $p>0.05$ & $p>0.05$ & $p>0.05$ \\
\hline
\end{tabular}

teins for individual subgroups of patients differing in the degree of malnutrition and comparison with the control group are shown in Table 2.

In the group of patients with moderate malnutrition (compared to those with mild and severe malnutrition) the median values of IL-6, sTLR4, A20, and HSP70 were the highest. In the study of the significance of differences between sTNFR1 protein values in the 3 subgroups with malnutrition (mild, moderate, severe) and the group with normal nutritional status, significant differences were found in each of the subgroups. However, no differences were found between individual subgroups with varying degrees of malnutrition. In the study of median STLR4 protein concentrations in the studied subgroups, values were not found to differ significantly. Compared to the control group, significant differences were found only for the mild and moderate malnutrition subgroups. In the case of protein A20 compared to the control group (normal nutritional status), significant differences were found only for subgroups with medium and severe malnutrition. There were also significant differences between moderate and severe malnutrition ( $p=0.0024)$, as well as for the subgroup with severe malnutrition compared to the group with mild and moderate malnutrition ( $p=0.0042)$.

In the TNF- $\alpha$, IL-1Ra protein studies, the highest median concentration values were found in the group of patients with severe malnutrition, but the increase in concentration with the degree of malnutrition was not a linear function, because the lowest values of these proteins were recorded in the subgroup with moderate malnutrition. In the case of TNF- $\alpha$, differences between individual subgroups and normal nutritional status were significant, but no differences were observed between severe, moderate and mild malnutrition (Table 2). At IL-1Ra levels, only the severe malnutrition subgroup showed significant differences from the control group. In the case of the MyD88 protein, the highest median values were observed in the sub-group with mild malnutrition, and the lowest in the sub-group with moderate malnutrition. Comparison of differences for each of the subgroups with the control group was significant. There were no significant differences between the subgroups with severe and moderate and mild malnutrition.

In the Kruskal-Wallis analysis regarding the distribution of protein concentrations in all compared groups, increased levels of sTNFR1 ( $p=0.0000)$ were found (Fig. 1) together with the severity of malnutrition. For other proteins - TNF- $\alpha$, IL-1Ra, IL-6, IL-10, sTLR4, MyD88, A20, HSP70, HMGB1 - no significant differences were found.

In studies on the correlation of malnutrition with the concentrations of examined proteins in patients treated in ICUs, it was found that as the degree of malnutrition increased, the levels of sTNFR1 increased ( $p=0.0000$, 


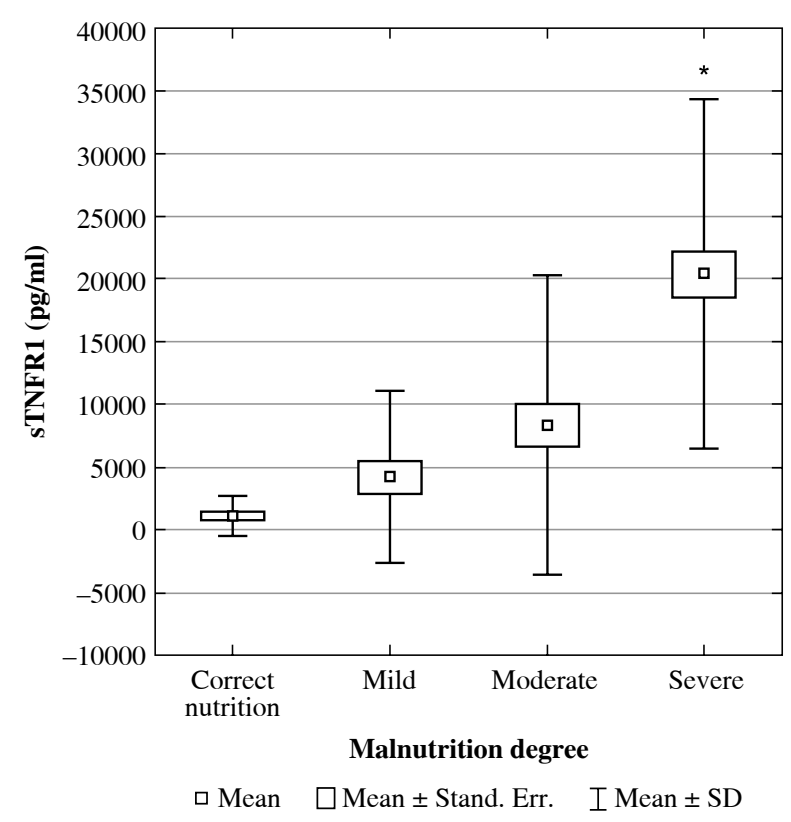

Fig. 1. Concentration of sTNFR1 protein depending on the degree of malnutrition

$R=0.5442)($ Fig. 2), and the concentration of A20 $(p=0.0313, R=-0.3112)$ decreased. For TNF- $\alpha$, IL-1Ra, IL-6, IL-10, MyD88, HSP70, HMGB1, sTLR4 proteins, no correlation was found between nutritional status and their concentrations.

In the subgroup of patients where malnutrition was a co-morbid disease with a severe infection, a significant correlation was found between the nutritional status and the concentration of tested proteins only in the case of the sTNFR1 protein $(p=0.0018, R=0.3914)$ (the more severe the malnutrition, the higher the sTNFR1 concentration). In the subgroup of malnourished patients without infections, a significant correlation between nutritional status and protein concentration was also found only for sTNFR1 ( $p=0.0003, R=0.4124$ ) (the more severe the malnutrition, the higher the sTNFR1 concentration).

A correlation was noted between the malnutrition status (NRS 2002) and the APACHE II severity score scale ( $p=0.0000, R=0.3382)$. In the group of deaths, $8(16 \%)$ cases with mild, $18(36 \%)$ with moderate and $24(48 \%)$ with severe malnutrition were reported. In the group of survivors there were 25 (22\%) with mild, 51 (45\%) with moderate and 37 (33\%) with severe malnutrition. Death was significantly more frequent in the group of patients who received 5 or more points on the NRS 2002 scale (severe malnutrition) on the first day of hospitalization in the ICU ( $p=0.0004)$ (Fig. 3).

In order to assess the prognostic value of the nutrition/ malnutrition study, protein concentrations were compared between patients who survived or died during ICU treatment. Patients who died with predominantly severe

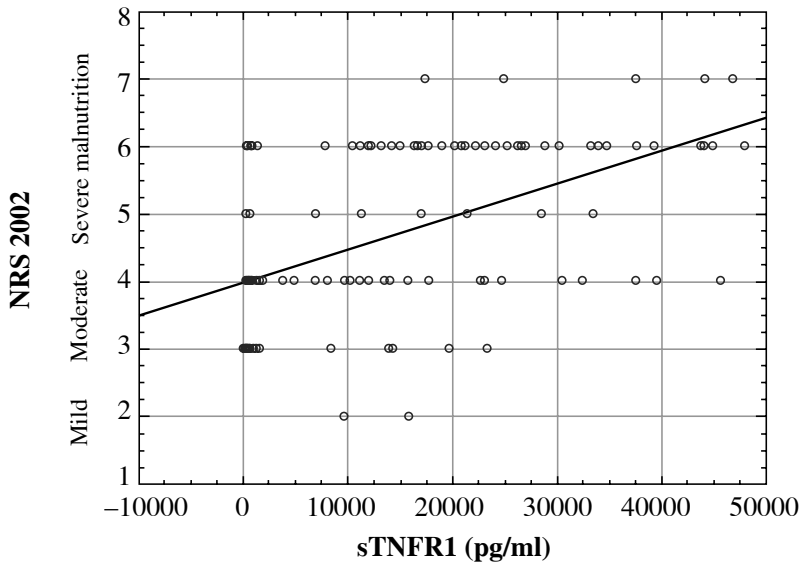

Fig. 2. Correlation of nutritional status assessed using the NRS 2002 scale and sTNFR1 protein concentration $(\mathrm{pg} / \mathrm{ml})(p=0.0000, R=0.5442)$

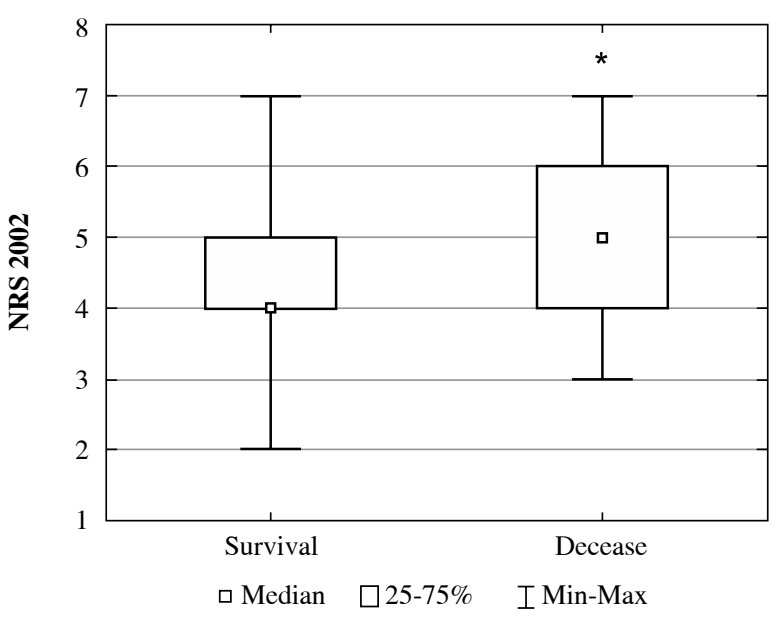

Fig. 3. Score on the NRS 2002 scale in the surviving group and in the group of deceased

malnutrition had significantly higher levels (medians in $\mathrm{pg} / \mathrm{ml}$ ) of the following proteins: sTNFR1 (25665.65, range: $9651.30-47921.30, p=0.0039)$, IL-6 (53.76, range: $8.40-960.49, p=0.0016)$, IL-10 (7.50, range: 0.00-339.41, $p=0.0217)$, HSP70 (0.25, range: $0.00-11.81, p=0.0165)$ compared to survivors: sTNFR1 (10353.00, range: 21.31 45572.80), IL-6 (46.61, range: 0.04-619.75), IL-10 (0.00, range: 0.00-918.69), HSP70 (0.08, range: 0.00-2.13). In the TNF- $\alpha$, MyD88, A20, IL-1Ra, sTLR4, and HMGB1 studies, no significant differences in protein concentrations were observed between the group of patients who died and the group of patients who survived $(p>0.05)$.

\section{Discussion}

The significant heterogeneity of the studied group of patients treated in ICUs and insufficient knowledge of the 
effect of nutritional status on immunity and the course of the disease are a common problem that makes it difficult to assess the effectiveness of new methods of diagnosis and treatment. Seriously ill patients treated in ICUs differ significantly in terms of the underlying disease, the level of malnutrition, the severity of immunity and metabolic disorders, the course of the disease, and the response to the implemented treatment, including nutrition. Although malnutrition is found in up to $100 \%$ of patients treated in ICUs and should be treated as a disease requiring treatment, professional and in-depth nutrition assessment is still not widely practiced. In critically ill patients, malnutrition may significantly affect the functioning of the immune system and directly affect the effectiveness of treatment and prognosis. In our study the statistical analysis of the test results confirmed the adverse effect of malnutrition, especially severe malnutrition (over 5 points on the NRS 2002 scale) on the severity of the condition of the patients and high mortality. Similar results (5.5 points) correlating with mortality were obtained in the study of Kosałka et al. [38]. Adverse effects of malnutrition are also confirmed by significant correlations of nutritional status with the APACHE II scale. It is known that in patients with normal nutritional status, metabolic response to stress and oxidative cell damage are less severe, and the immune system retains greater ability to modulate/autoregulate to maintain homeostasis. In critically ill patients, this is extremely important due to the simultaneous intensification of the dynamics of the pro and anti-inflammatory response. One of the reasons for the lack of unequivocal successes (reduction of mortality) in conducting causal treatment of severe infections, as well as nutritional treatment, including immunonutrition, is the lack of effective biomarkers of malnutrition reflecting the current state of the immune system. Administering nutritional mixtures at the wrong time or composition may result in increased SIRS-type responses or increased immunosuppression and mortality [39]. It seems that only the early detection of malnutrition and the accompanying changes in immunity (anticipating irreversible metabolic, immunological and organ damage) and monitoring of malnutrition and selected resistance parameters can result in the proper selection of nutritional treatment, and by improving (controlling) the state of nutrition, affect the decrease mortality.

The results of the present study clearly show significant differences in the concentration of the majority of proteins tested in the peripheral blood, depending on the degree of malnutrition. These differences translate into the course of the immune response. Various markers have been used in the laboratory routine assessment of nutritional status so far [40], such as albumin, prealbumin, transferrin, total lymphocyte count, and acute phase protein (C-reactive protein - CRP). However, due to the very dynamic course of the disease in critically ill patients treated in ICUs, these markers are still of limited use in the diagnosis of malnutrition due to the long half-life and relatively late changes in blood levels since the activation of the immune system.

As demonstrated by our own research, malnutrition and dysregulated immune response assessed on the basis of changes in the concentration of selected cytokines and TLR4 signalling proteins may be an important diagnostic indicator in patients treated in ICUs. Earlier detection of nutrition disorders and the resulting changes in the quality of the immune response to patients' severe conditions (trauma [29], burns [41], cancers [42-44]) may result in better "targeted" therapy selection (including selection of the type and dose of nutritional mixtures), treatment results and mortality. The methods of assessing nutritional status used so far (e.g. NRS 2002, SGA, MUST screening scales), also used in seriously ill patients, are still not very effective in early detection of malnutrition and have an insufficient effect on improving treatment results [38, 40]. This results, among other causes, from the high dynamics of changes in the nutritional status of these patients, variability of the healing process in individual patients and "mismatches" of methods of assessing nutritional status in relation to the clinical condition of the patient.

The results of the conducted research indicate an increased concentration of pro-inflammatory proteins, e.g. IL-6, TNF- $\alpha$, with simultaneous increase of anti-inflammatory cytokines, e.g. IL-1Ra, in malnourished patients. It is known that malnutrition can potentiate these opposing processes, ultimately leading to immunosuppression. Malnutrition has been shown to affect hemopoiesis, and the production and function of immune cells. LPS-induced sepsis showed a reduction in the release of leukocytes from the bone marrow, as well as their impaired maturation [45]. Santos et al. [15] evaluated the effect of malnutrition on the biological and immunomodulatory functions of mesenchymal marrow cells (MSCs). MSCs have immunomodulatory properties through the production and secretion of soluble factors such as cytokines, chemokines, growth factors and through direct contact with other cells. MSCs have both pro-inflammatory and anti-inflammatory effects and are involved in the regulation of the immune response as well as in tissue repair and regeneration. Studies have shown that protein malnutrition modifies the immunosuppressive properties of mesenchymal cells, including by reducing NF- $\mathrm{\kappa B}$ expression, and TNF- $\alpha$ production, and increasing IL-10 expression in macrophages and reducing IL-10 expression in lymphocytes [46]. An increase in IL-6 concentration was found in the malnourished group. In the study, after cell exposure to lipopolysaccharides (LPS), a decrease in macrophage and lymphocyte proliferation, physiologically induced by MSC, was also observed. However, under malnutrition, the proliferation of immune cells has been limited, including due to increased IL-6 levels [15, 47].

To date, IL-6, as one of the few immunological parameters, is used to assess nutritional status (malnutrition 
detection) [48]. An increase in proinflammatory cytokines (e.g. IL-6) is seen in most patients treated in ICUs. The predictive value of this cytokine in the assessment of malnutrition and mortality was confirmed in cardiovascular diseases [49, 50], diseases requiring chronic haemodialysis [51], end-stage renal failure [49], and lung cancer [52]. Based on the present research results, the use of IL- 6 as a marker of malnutrition with prognostic significance in the ICU may raise doubts. As a result of our previous research, it was found that the concentration of IL-6 in patients who died as a result of infection was significantly lower than in patients who survived [53]. However, in the case of patients who died from other causes, IL-6 levels were higher than in the case of survivors. It follows that in severe infections, IL-6 is affected by many opposing factors. Based on the study, the disadvantages of IL- 6 as a marker of ICU malnutrition also include the inability to differentiate between different levels of malnutrition, as well as the lack of correlation between the concentration of this cytokine and the increasing degree of malnutrition. The extension of routine diagnostics of nutritional status by more accurate assessment of the inflammatory response based on the levels of proinflammatory and anti-inflammatory cytokines (IL-6, IL-10, IL-1Ra or sTNFR1) gives some hope for improved treatment results [54, 55].

It should be emphasized that sTNFR 1 protein had the highest diagnostic and prognostic effectiveness in the conducted studies. The use of this protein as a biomarker can have several advantages. In addition to the diagnosis of malnutrition, assessing the concentration of sTNFR1 protein allows one to differentiate the degree of malnutrition (as the degree of malnutrition worsens, the risk of death increases). In the group of examined proteins, only in the case of sTNFR1 protein was an increasing tendency observed (like a linear relationship) between the deterioration of the degree of malnutrition and the increase in the concentration of protein, which was confirmed by the finding of a strong correlation $(p=0.0000, R=0.5442)$. As demonstrated in our previous studies, sTNFR1 is an effective marker of severe infections and enables early differential diagnosis with other causes of the severe condition of patients treated in the ICU [53]. Also when the reason for hospitalization in the ICU is other than severe infections (injuries, heart failure, respiratory failure, kidneys), sTNFR1 protein has a strong correlation with the state of nutrition ( $p=0.0003, R=0.4124)$ (the more severe the malnutrition, the greater the sTNFR1 concentration). The sTNFR1 concentration was significantly higher in the group of patients who died. The prognostic value of the STNFR1 protein is also confirmed by our previous studies, in which the ROC analysis for the sTNFR1 protein (AUC $=0.711(0.91,0.48))$ determined a cut-off point of 16367.6 $\mathrm{pg} / \mathrm{ml}$, which corresponds to the values measured in severe malnutrition [53]. In the research of Sauerwein et al. [16], using immune mediators to assess protein-energy malnu- trition in Kenyan children, increased levels of sTNFR1, IL- 6 and CRP were found. There was also no difference in the concentration of soluble IL- 6 and IL-1Ra in the group of malnourished and healthy children. Increasing sTNFR1 levels in energy protein malnutrition was also found in our study. The opposite results for IL-6 and IL-Ra are likely due to the different aetiologies of malnutrition. In the research of Sauerwein et al. [16], malnutrition was due to nutritional deficiencies, while in the group we studied, malnutrition was the result of stress and illness as well as severe infection. A similar explanation applies to discrepancies with research results of Oliveira et al. [56], where in the study of malnourished mice there was a decrease in sTNFR1 protein expression in macrophages. The study involved inducing protein malnutrition. After a $20 \%$ decrease in body weight, peritoneal macrophages were collected, and macrophages were observed from in vitro and malnourished mice in vitro, with or without TNF- $\alpha$. Decreased expression of sTNFR1 and its signalling pathway proteins, as well as a decrease in expression and a decrease in phosphorylation (activation) of $\mathrm{NF}-\kappa \mathrm{B}$, and a decrease in the concentration of effectors (IL-1 $\beta$, IL-12) were observed. Malnutrition has been found to interfere with macrophage activation and the ability of these cells to react in the innate immune response [56]. Increased sTNFR1 levels have been reported for severe infections and injuries [29, 53]. It was noted that the cells of the immune system retain the ability to produce high concentrations of sTNFR1, despite the severe condition of the patients and malnutrition. Perhaps this is part of the advanced CARS ( $5^{\text {th }}$ degree) anti-inflammatory compensatory reaction [57], aimed at achieving homeostasis, but at the same time increasing the risk of multiorgan failure and death. Such significant amounts of protein produced are one of the reasons for the rapidly growing and difficult to compensate malnutrition.

In conclusion, the results of the study show that nutritional disorders can be an independent factor affecting clinical results and should be diagnosed and monitored as early as possible, as well as included in therapy (overriding need for compensation of protein deficiency $[58,59]$, followed by energy, and substances necessary for leukocyte function). It seems that only early detection of malnutrition and accompanying changes in immunity (anticipating irreversible metabolic, immunological and organ damage) and monitoring of malnutrition and selected resistance parameters can result in proper selection of nutritional treatment. The use of the sTNFR1 marker protein is promising and responds to the need for more effective indicators that can not only be used to assess the severity of malnutrition and immune disorders in the first hours after admission to the ICU, but also have significant prognostic value (risk of death). It should be presumed that without an early diagnosis of innate immunity disorders, attempts to modulate them may not be effective in most cases of critically ill patients treated in the ICU, because the concentration of 
these proteins varies depending on the severity of the patient's condition and the nutritional status.

\section{The authors declare no conflict of interest.}

\section{References}

1. Stoller J, Halpin L, Weis M, et al. (2016): Epidemiology of severe sepsis: 2008-2012. J Crit Care 31: 58-62.

2. Rimmer E, Doucette S, Houston DS, et al. (2018): White blood cell count trajectory and mortality in septic shock: a retrospective cohort study. Blood 132: 3691.

3. Lew CCH, Wong GJY, Cheung KP, et al. (2018): Association between malnutrition and 28-day mortality and intensive care length-of-stay in the critically ill: a prospective cohort study. Nutrients 10: 10.

4. Mogensen KM, Robinson MK, Casey JD, et al. (2015): Nutritional status and mortality in the critically ill. Crit Care Med 43: 2605-2615.

5. McClave SA, Taylor BE, Martindale RG, et al. (2016): Guidelines for the Provision and Assessment of Nutrition Support Therapy in the Adult Critically Ill Patient: Society of Critical Care Medicine (SCCM) and American Society for Parenteral and Enteral Nutrition (A.S.P.E.N.). JPEN J Parenter Enteral Nutr 40: 159-211.

6. Stratton RJ, Green CJ, Elia M (2003): Disease-related malnutrition: an evidence-based approach to treatment. CABI Publishing, Wallingford, UK.

7. Singer P, Blaser AR, Berger MM, et al. (2019): ESPEN guideline on clinical nutrition in the intensive care unit. Clin Nutr 38: 48-79.

8. Fiaccadori E, Zambrelli P, Tortorella G (1995): Physiopathology of respiratory muscles in malnutrition. Minerva Anestesiol 61: 93-99.

9. Keusch GT (2003): The history of nutrition: malnutrition, infection and immunity. J Nutr 133: 336S-340S.

10. Kikuchi M, Inagaki T, MiyagawaK, et al. (2006): Risk factors of disseminated intravascular coagulation in septic systemic inflammatory response syndrome in nursing home residents. Geriatr Gerontol 6: 109-115.

11. Cunha MC, Lima Fda S, Vinolo MA, et al. (2013): Protein malnutrition induces bone marrow mesenchymal stem cells commitment to adipogenic differentiation leading to hematopoietic failure. PLoS One 8: e58872.

12. Calder PC (2013): Feeding the immune system. Proc Nutr Soc 72: 299-309.

13. Abdallaha A, Gharrafa H, Okashab H (2014): Early ICU energy deficit: Is it a risk factor for ventilator-associated pneumonia? Egypt J Chest Dis Tuberculosis 63: 3-7.

14. Rytter MJ, Kolte L, Briend A, et al. (2014): The immune system in children with malnutrition - a systematic review. PLoS One 9: e105017.

15. Dos Santos GG, Batool S, Hastreiter A (2017): The influence of protein malnutrition on biological and immunomodulatory aspects of bone marrow mesenchymal stem cells. Clin Nutr 36: 1149-1157.

16. Sauerwein RW, Mulder JA, Mulder L, et al. (1997): Inflammatory mediators in children with protein-energy malnutrition. Am J Clin Nutr 65: 1534-1539.

17. Chandra RK (2002): Nutrition and the immune system from birth to old age. Eur J Clin Nutr 5 (Suppl 3): S73-76.
18. Sakamoto M, Fujisawa Y, Nishioka K (1998): Physiologic role of the complement system in host defense, disease, and malnutrition. Nutrition 14: 391-398.

19. Mellman I, Steinman RM (2001): Dendritic cells: specialized and regulated antigen processing machines. Cell 106: 255258.

20. Hotchkiss RS, Monneret G, Payen D (2013): Immunosuppression in sepsis: a novel understanding of the disorder and a new therapeutic approach. Lancet Infect Dis 13: 260-268.

21. Schaible UE, Kaufmann SH (2007): Malnutrition and infection: complex mechanisms and global impacts. PLoS Med 4: e115.

22. Lew CCH, Yandell R, Fraser RJL, et al. (2017): Association between malnutrition and clinical outcomes in the intensive care unit: a systematic review. JPEN J Parenter Enteral Nutr 41: 744-758.

23. Berger MM, Chioléro RL, Pannatier A, et al. (1997): A 10year survey of nutritional support in a surgical ICU: 19861995. Nutrition 13: 870-877.

24. Koretz RL (1995): Nutritional supplementation in the ICU. How critical is nutrition for the critically ill? Am J Respir Crit Care Med 151: 570-573.

25. Singer M, Deutschman CS, Seymour CW, et al. (2016): The third international consensus definitions for sepsis and septic shock (Sepsis-3). JAMA 315: 801-810.

26. Cox CE (2012): Persistent systemic inflammation in chronic critical illness. Respir Care 57: 859-866.

27. Mira JC, Gentile LF, Mathias BJ, et al. (2017): Sepsis pathophysiology, chronic critical illness and PICS. Crit Care Med 45: 253-262.

28. Sharma K, Mogensen KM, Robinson MK (2018): Pathophysiology of critical illness and role of nutrition. Nutr Clin Pract 34: $12-22$.

29. Bińkowska AM, Michalak G, Słotwiński R (2015): Current views on the mechanisms of immune responses to trauma and infection. Cent Eur J Immunol 40: 206-216.

30. Cuenca AG, Delano MJ, Kelly-Scumpia KM, et al. (2011): A paradoxical role for myeloid-derived suppressor cells in sepsis and trauma. Mol Med 17: 281-292.

31. Moore FA, Phillips SM, McClain CJ, et al. (2017): Nutrition support for persistent inflammation, immunosuppression, and catabolism syndrome. Nutr Clin Pract 32 (Suppl 1): 121S-127S.

32. Stechmiller JK, Childress B, Porter T (2004): Arginine immunonutrition in critically ill patients: a clinical dilemma. Am J Crit Care 13: 17-23.

33. Dellinger RP, Levy MM, Rhodes A, et al. (2013): Surviving Sepsis Campaign: International guidelines for management of severe sepsis and septic shock. Crit Care Med 41: 580-637.

34. Singer P, Anbar R, Cohen J, et al. (2011): The tight calorie control study (TICACOS): a prospective, randomized, controlled pilot study of nutritional support in critically ill patients. Inten Care Med 37: 601-609.

35. Bone RC, Balk RA, Cerra FB, et al. (1992): Definitions for sepsis and organ failure and guidelines for the use of innovative therapies in sepsis. The ACCP/SCCM Consensus Conference Committee American College of Chest Physicians/ Society of Critical Care Medicine. Chest 101: 1644-1655.

36. Levy MM, Fink MP, Marshall JC, et al. (2001): SCCM/ ESICM/ACCP/ATS/SIS International Sepsis Definitions Conference. Crit Care Med 31: 1250-1256.

37. Kondrup J, Allison SP, Elia M, et al. (2002): ESPEN guidelines for nutrition screening 2002. Clin Nutr 22: 415-421. 
38. Kosałka K, Wachowska E, Słotwiński R (2017): Disorders of nutritional status in sepsis - facts and myths. Prz Gastroenterol 12: 73-82.

39. Heyland D, Muscedere J, Wischmeyer PE, et al. (2013): A randomized trial of glutamine and antioxidants in critically ill patients. N Engl J Med 368: 1489-1497.

40. Berger MM, Reintam-Blaser A, Calder PC, et al. (2019): Monitoring nutrition in the ICU. Clin Nutr 38: 584-593.

41. Hur J, Yang HT, Chun W, et al. (2015): Inflammatory cytokines and their prognostic ability in cases of major burn injury. Ann Lab Med 335: 105-110.

42. Lin WW, Karin M (2007): A cytokine-mediated link between innate immunity, inflammation, and cancer. J Clin Invest 117: 1175-1183.

43. Williams AE, Perry MM, Moschos SA, et al. (2008): Role of miRNA-146a in the regulation of the innate immune response and cancer. Biochem Soc Trans 36: 1211-1215.

44. Cui J, Chen Y, Wang HY, Wang RF (2014): Mechanisms and pathways of innate immune activation and regulation in health and cancer. Hum Vaccin Immunother 10: 3270-3285.

45. Fock RA, Vinolo MAR, Blatt SL, Borelli P (2012): Impairment of the hematological response and interleukin-1 $\beta$ production in protein-energy malnourished mice after endotoxemia with lipopolysaccharide. Braz J Med Biol Res 45: 1163-1171.

46. Fock RA, Vinolo MA, Crisma AR, et al. (2008): Protein-energy malnutrition modifies the production of interleukin-10 in response to lipopolysaccharide (LPS) in a murine model. J Nutr Sci Vitaminol 54: 371-377.

47. Clutterbuck R, Powles R, Millar J, Catovsky D (2000): Interleukin-6 and other gp130-dependent cytokines selectively inhibit proliferation of macrophage-lineage hemopoietic progenitor cells. Exp Hematol 28: 1120-1128.

48. Mulherin DW, Cogle SV (2017): Updates in nutrition support for critically ill adult patients. Hosp Pharm 52: 17-26.

49. Honda H, Qureshi AR, Heimbürger O, et al. (2006): Serum albumin, C-reactive protein, interleukin 6 , and fetuin a as predictors of malnutrition, cardiovascular disease, and mortality in patients with ESRD. Am J Kidney Dis 47: 139-148.

50. Perunicic-Pekovic G, Pljesa S, Rasic-Milutinovic Z, et al. (2008): Inflammatory cytokines and malnutrition as related to risk for cardiovascular disease in hemodialysis patients. Can J Physiol Pharmacol 86: 205-209.

51. Kaizu Y, Kimura M, Yoneyama T, et al. (1998): Interleukin-6 may mediate malnutrition in chronic hemodialysis patients. Am J Kidney Dis 31: 93-100.

52. Songür N, Kuru B, Kalkan F (2004): Serum interleukin-6 levels correlate with malnutrition and survival in patients with advanced non-small cell lung cancer. Tumori 90: 196-200.

53. Stelmasiak M, Mikaszewska-Sokolewicz M, Niewiński G, et al. (2020): The soluble tumor necrosis factor receptor I as a potential early diagnostic and prognostic marker in intensive care units patients with severe infections. Cent Eur J Immunol 45: $160-169$.

54. Słotwiński R, Szczygieł B, Szabłowski A, et al. (2004): Polish changes in interleukin 6 and cytokine antagonists (IL-1 ra and sTNFRI) serum concentration in patients after esophagectomy for esophageal cancer receiving nutritional support both preand postoperatively. Pol Oncol 7: 169-176.

55. Słotwiński R, Olszewski WL, Lech G, et al. (2007): Can the interleukin-1 receptor antagonist (IL-1Ra) be a marker of anti-inflammatory response to enteral immunonutrition in malnourished patients after pancreaticoduodenectomy? J Pancreas 8: 759-769.
56. Oliveira DC, Hastreiter AA, Mello AS, et al. (2014): The effects of protein malnutrition on the TNF-RI and NF- $\kappa B$ expression via the TNF- $\alpha$ signaling pathway. Cytokine 69: 218-225.

57. Bone RC (1996): Immunologic dissonance: a continuing evolution in our understanding of the systemic inflammatory response syndrome (SIRS) and the multiple organ dysfunction syndrome (MODS). Ann Intern Med 125: 680-687.

58. Dickerson RN, Boschert KJ, Kudsk KA, Brown RO (2002): Hypocaloric enteral tube feeding in critically ill obese patients. Nutrition 18: 241-246.

59. Wischmeyer PE (2019): Nutrition therapy in sepsis. Crit Care Clin 34: 107-125. 